\title{
Erratum to: Prediction of Drug-Drug Interactions Between Various Antidepressants and Efavirenz or Boosted Protease Inhibitors Using a Physiologically Based Pharmacokinetic Modelling Approach
}

\author{
Marco Siccardi • Catia Marzolini · Kay Seden • \\ Lisa Almond • Anna Kirov • Saye Khoo • \\ Andrew Owen · David Back
}

Published online: 30 April 2013

(C) Springer International Publishing Switzerland 2013

\section{Erratum to: Clin Pharmacokinet}

DOI 10.1007/s40262-013-0056-7

A Published-Ahead-of-Print version of this article was made available online at http://link.springer.com/journal/ 40262/onlineFirst/page/1 on 12 March 2013. An error has subsequently been identified in that version of the article, and the following correction should be noted:

Table 2, which was incorrectly formatted, should appear as:

The online version of the original article can be found under doi:10.1007/s40262-013-0056-7.

M. Siccardi $(\bowtie) \cdot$ K. Seden · A. Kirov - S. Khoo - A. Owen ·

D. Back

Department of Molecular and Clinical Pharmacology,

Institute of Translational Medicine, University of Liverpool,

70 Pembroke Place, Liverpool L69 3GF, UK

e-mail: siccardi@liverpool.ac.uk

C. Marzolini

Division of Infectious Diseases and Hospital Epidemiology,

University Hospital Basel, Basel, Switzerland

L. Almond

Simcyp Limited, Sheffield, UK 


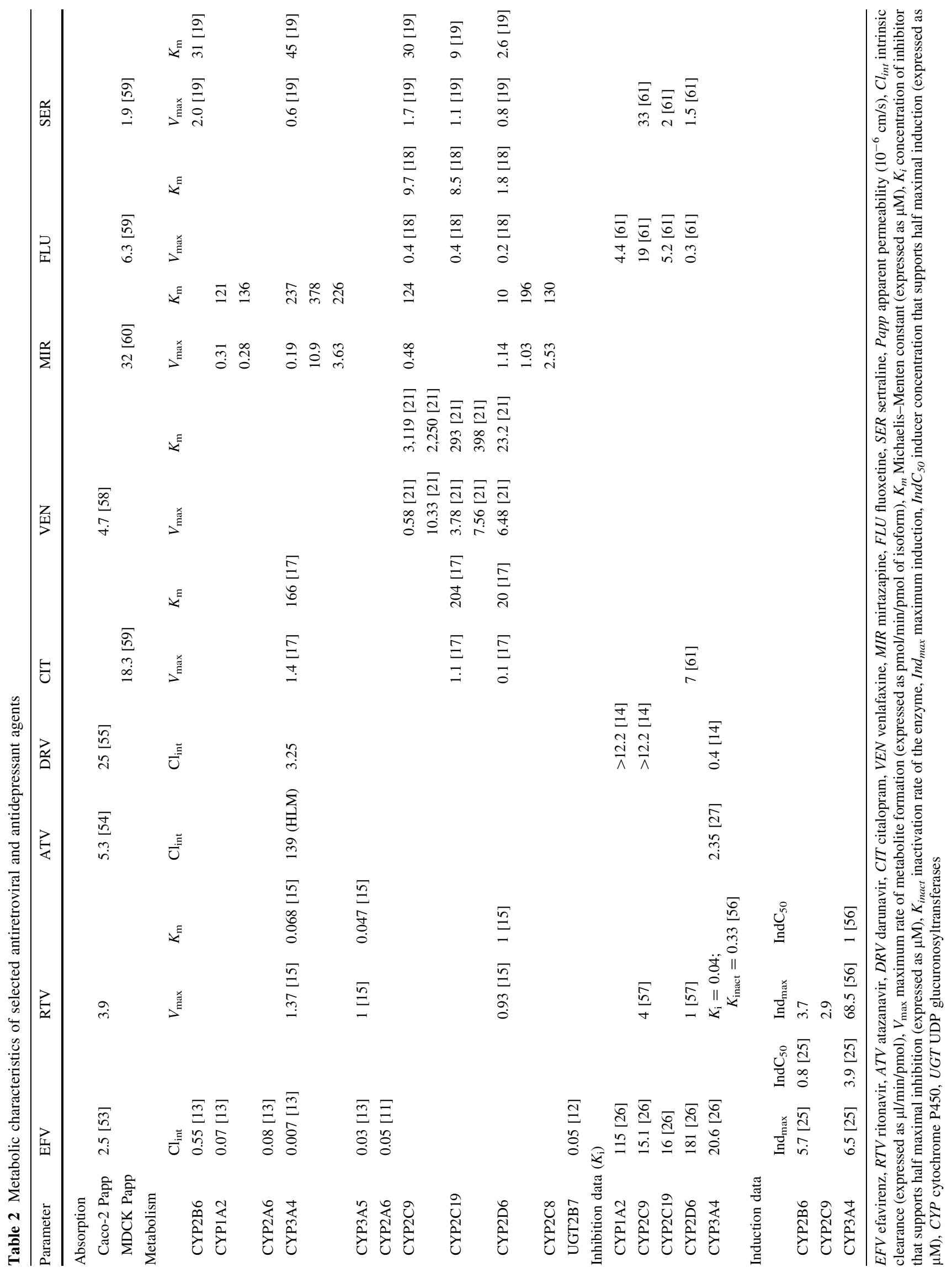

